Original Article

\title{
Comparison between syntocinon, misoprostol and carbetocin in reducing blood loss in elective caesarean section
}

\author{
Elgazayerli W.S.
}

Department of Obstetrics and Gynecology, Faculty of Medicine, Alexandria University

\begin{abstract}
Objective: To compare the effectiveness and safety of carbetocin, misoprostol and syntocinon in reducing the amount of blood loss following cesarean deliveries.

Patients and Methods: This randomized study was carried out on 180 attended for delivery. A double-blind randomized controlled trial enrolled patients with a singleton pregnancy scheduled for an elective cesarean delivery. The primary outcome was the amount of blood loss. The secondary outcome was the occurrence of uterine atony necessitating additional uterotonics. Per-protocol analyses were performed. Patients, investigators and data analysts were masked to treatment assignments.

Results: It was found that the carbetocin group showed a significant decrease in blood loss intra and post-operative. Also, the decrease in both $\mathrm{Hb}$ and Hct level was significantly lower than the other two drugs. On the other hand, the complication and side effect of carbetocin were significantly lower than the other two drugs.

Conclusion: Additional uterotonics were needed less frequently by patients treated with carbetocin. Carbetocin was superior to syntocinon and misoprostol in reducing the blood loss and preventing uterine atony following an elective cesarean delivery.
\end{abstract}

Key Words: Caesarean section, carbetocin, misoprostol, syntocinon.

Received: 15 February 2019, Accepted: 2 April 2019

Corresponding Author: Elgazayerli W.S., MD, Department of Gynecology, Faculty of Medicine, Alexandria University, Egypt, Tel.: +2 01224283287, E-mail: welgazayerli@yahoo.com

ISSN: 2090-7265, August 2019, Vol. 9, No. 3

\section{INTRODUCTION:}

Globally, cesarean delivery is one of the most common major operations that women undergo and its rate is increasing worldwide ${ }^{[1]}$. Postpartum hemorrhage (PPH) following cesarean delivery is a significant problem and a major cause of maternal mortality ${ }^{[2]}$. WHO defines PPH as blood loss of at least $500 \mathrm{~mL}$ within 24 hours of delivery ${ }^{[3]}$.

Patients benefit from reductions in operative blood loss during cesarean delivery through decreased postoperative morbidity and reduced exposure to the risks associated with blood transfusions ${ }^{[4]}$. The commonest cause of hemorrhage during delivery is uterine atony; consequently, it has been agreed that during delivery active management of the third stage of labor is preferable to expectant management ${ }^{[5]}$. Active management of third stage of labor includes controlled cord traction for the expulsion of the placenta during a cesarean delivery and the administration of intramuscular or intravenous syntocinon ${ }^{[3]}$.

Consequently, the administration of uterotonic drugs during cesarean section (CS) and in the third stage of labor for vaginal delivery has become essential to diminish the risk of $\mathrm{PPH}$ and improve maternal safety ${ }^{[6]}$.
Syntocinon is a widely used and effective first choice uterotonic agent in the universal prevention of PPH. ${ }^{[7,8]}$ It binds to syntocinon receptors of the myometrium and stimulates uterine muscle contraction where it increases the intracellular calcium concentration. ${ }^{[9]}$ However, there are some limitations of its use, beside syntocinon has a short half-life of few minutes, and a continuous intravenous (IV) infusion is mandatory to have sustained uterine contraction. ${ }^{[10,11]}$ Moreover, many side effects are associated with large doses or boluses of Syntocinon as hypotension, nausea, vomiting, severe water intoxication with or without seizures, dysrhythmias, ST-T changes and pulmonary edema. ${ }^{[12]}$

Misoprostol, a prostaglandin E1 (PGE1) analogue, has potent uterotonic action is cheap and stable at room temperature and has few adverse effects. It is well absorbed when administered by oral, vaginal, sublingual, rectal or buccal routes ${ }^{[13]}$.

The sublingual route is recognized as having the greatest benefit due to its rapid uptake, long-acting effect and the greatest bioavailability compared with other routes of misoprostol administration ${ }^{[14]}$. 
Carbetocin is a synthetic analogue of human syntocinon with structural modifications that increase its half life thereby prolonging its pharmacological effects ${ }^{[15]}$. Two double-blind randomized trials compared $100 \mathrm{lg}$ carbetocin (the licensed dose) with different combinations of syntocinon, bolus and infusion following caesarean section. The first trial ${ }^{[16]}$ found that significantly more women needed additional oxytocic interventions in the syntocinon group. The second trial found no significant differences in the intraoperative blood loss ${ }^{[17]}$.

With a plasma half-life of 40 minutes, carbetocin has a longer duration of action than oxytocin. It is indicated for the prevention of uterine atony and $\mathrm{PPH}$ following elective CS under epidural or spinal anaesthesia. Intravenous injection of carbetocin produces rhythmic uterine contractions lasting approximately 60 minutes, while IM injection significantly prolongs its activity $\sim 120$ minutes $^{[18]}$.

\section{AIM OF THE WORK:}

The aim of the present study was to evaluate the effectiveness and side effects of carbetocin, misoprostol and syntocinon in the prevention of $\mathrm{PPH}$ in patients undergoing elective cesarean deliveries.

\section{PATIENTS AND METHOD}

This randomized study was carried out on 180 pregnant women attended for delivery in El-Shatby Maternal Hospital, Faculty of Medicine.

\section{Inclusion criteria}

Women with a singleton pregnancy undergoing elective or emergency caesarean section after 37 weeks of gestation.

\section{Exclusion criteria}

Patients with blood diseases as thrombocytopenia and coagulation defect, renal and liver diseases, hypersensitivity to carbetocin and any contraindication for misoprostol as bronchial asthma were excluded from the study. Spinal anesthesia technique was standardized for all groups.

\section{Patients were classified into 3 groups}

\section{Group A:}

This group included 60 cases (Syntocinon group) received $20 \mathrm{IU}$ of syntocinon iv infusion on $1000 \mathrm{ml}$ of normal saline solution during cesarean section after delivery of the baby.

\section{Group B:}

This group included 60 cases (Misoprostol group) received misoprostol $400 \mathrm{ug}$ per rectum immediately before induction of anesthesia in operating theater.

\section{Group C:}

This group included 60 cases (Carbetocin group) in which (PAPAL) $100 \mathrm{mg}$ was administered iv slowly during cesarean section after delivery of the baby.

\section{Ethics:}

Ethics committee approved the study and a written informed consent was obtained from each patient before the study commenced.

\section{Primary outcome:}

Estimated blood loss, difference in preoperative and postoperative hemoglobin and hematocrit and incidence of uterine atony.

\section{Statistical methods:}

The results were expressed as mean $\pm \mathrm{SD}$ or number and $(\%)$. Comparison between categorical data was performed using ANOVA test. The data was considered significant if p-values $<0.05$. Statistical analysis was performed with the aid of the SPSS (version 21.0) computer program.

\section{RESULTS:}

(Table 1) showed the demographic and basic maternal data of the patients involved in this study. The age, BMI, gestational age, gravidity and parity in the three studied groups showed insignificant differences between them.

The data of primary outcome was illustrated in (Table 2). The intraoperative blood loss was higher in group A (syntocinon group) $(660.0 \pm 36.2 \mathrm{ml})$; while group C (carbetocin group) showed the least amount of blood loss. The decrease in hemoglobin and hematocrit in carbetocin group was more significant than the other two groups. The need for blood transfusion in group A was 4 cases, while for group $\mathrm{C}$ no one needed blood transfusion.

The side effects and complications of the three drugs were shown in (Table 3). There was a significant increase in complication in groups A and B more than group C. 
Table 1: Comparison between the three studied groups regarding basic and characteristic feature.

\begin{tabular}{|c|c|c|c|c|}
\hline & $\begin{array}{c}\text { Group A } \\
\text { Syntocinon gp. } \\
\text { "n=60" }\end{array}$ & $\begin{array}{c}\text { Group B } \\
\text { Misoprostol gp. } \\
\text { "n=60" }\end{array}$ & $\begin{array}{c}\text { Group C } \\
\text { Carbetocin gp. } \\
\text { "n=60" }\end{array}$ & $\mathrm{p}$ \\
\hline Age (years) & $26.2 \pm 4.6$ & $24.6 \pm 5.21$ & $25.6 \pm 3.98$ & 0.236 \\
\hline BMI & $27.2 \pm 3.98$ & $28.1 \pm 4.01$ & $27.9 \pm 3.85$ & 0.452 \\
\hline Gestational age at delivery & $38.7 \pm 0.76$ & $39.1 \pm 0.77$ & $38.8 \pm 0.67$ & 0.630 \\
\hline Gravidity & $2.11 \pm 0.65$ & $2.08 \pm 0.56$ & $1.99 \pm 0.61$ & 0.405 \\
\hline Parity & $1.12 \pm 0.36$ & $1.03 \pm 0.41$ & $1.00 \pm 0.38$ & 0.398 \\
\hline
\end{tabular}

Table 2: Comparison between the three studied groups regarding intra and post operative blood loss and hematocrit pre and post-operative.

\begin{tabular}{lccc}
\hline & $\begin{array}{c}\text { Group A } \\
\text { Syntocinon gp. } \\
\text { "n=60" }\end{array}$ & $\begin{array}{c}\text { Group B } \\
\text { Misoprostol gp. } \\
\text { "n=60" }\end{array}$ & $\begin{array}{c}\text { Group C } \\
\text { Carbetocin gp. } \\
\text { "n=60" }\end{array}$ \\
\hline Intraoperative blood loss, $\mathrm{mL}$ & $660.0 \pm 36.2$ & $590.3 \pm 58.2$ & $436.2 \pm 36.2$ \\
Postoperative blood loss, $\mathrm{mL}$ & $153.5 \pm 10.2$ & $142.4 \pm 11.9$ & $61.2 \pm 8.2$ \\
Hemoglobin (g/dl) & $10.95 \pm 0.98$ & $10.73 \pm 1.01$ & $0.0025^{*}$ \\
Pre-operative & $10.03 \pm 0.88$ & $10.11 \pm 0.98$ & $10.68 \pm 0.88$ \\
Post-operative & & $32.62 \pm 3.25$ & 0.93 \\
Haematocrit value & $33.08 \pm 2.1$ & $27.5 \pm 2.81$ & $33.0 \pm 2.04$ \\
Pre-operative & $28.3 \pm 2.07$ & 3 & $30.2 \pm 2.33$ \\
Post-operative & 4 & $0.016^{*}$ \\
Need for blood transfusion & & 0.401 \\
\hline
\end{tabular}

Table 3: Comparison between the three studied groups regarding complication

\begin{tabular}{|c|c|c|c|c|c|c|c|}
\hline & \multicolumn{2}{|c|}{$\begin{array}{c}\text { Group A } \\
\text { Syntocinon gp. } \\
\text { "n=60" }\end{array}$} & \multicolumn{2}{|c|}{$\begin{array}{c}\text { Group B } \\
\text { Misoprostol gp. } \\
\text { "n=60" }\end{array}$} & \multicolumn{2}{|c|}{$\begin{array}{c}\text { Group C } \\
\text { Carbetocin gp. } \\
\text { " } \mathrm{n}=60 "\end{array}$} & \multirow[t]{2}{*}{$\mathrm{p}$} \\
\hline & No. & $\%$ & No. & $\%$ & No. & $\%$ & \\
\hline Headache & 12 & 20.0 & 11 & 18.3 & 8 & 13.3 & $0.036^{*}$ \\
\hline Heat sensation & 11 & 18.3 & 14 & 23.3 & 9 & 15.0 & $0.041 *$ \\
\hline Abdominal pain & 32 & 53.3 & 28 & 46.7 & 35 & 58.3 & 0.214 \\
\hline Palpitations & 23 & 38.3 & 16 & 26.7 & 11 & 18.3 & $0.024 *$ \\
\hline Metallic taste & 3 & 5.0 & 6 & 10.0 & 1 & 1.7 & $0.006^{*}$ \\
\hline Fever & 7 & 11.7 & 6 & 10.0 & 4 & 6.7 & $0.037^{*}$ \\
\hline Shivering & 8 & 13.3 & 10 & 16.7 & 4 & 6.7 & 0.081 \\
\hline Nausea & 6 & 10.0 & 7 & 11.7 & 6 & 10.0 & 0.622 \\
\hline Vomiting & 4 & 6.7 & 3 & 5.0 & 3 & 5.0 & 0.41 \\
\hline Pruritus & 2 & 3.3 & 2 & 3.3 & 1 & 1.7 & 0.398 \\
\hline
\end{tabular}

\section{DISCUSSION:}

There was no statistically significant difference between the three groups as regard to demographic data (maternal age, BMI, parity or gestational age).

In the present study, hemoglobin level and hematocrit value assessment preoperatively and 24 hours postoperatively after elective cesarean delivery had a mildly significant difference among the three studied groups $(\mathrm{p}<0.05)$; so, carbetocin prevent or minimize incidence of post cesarean delivery hemorrhagic anemia.
A single dose of $100 \mu \mathrm{g}$ of carbetocin given with intravenous drip has been proved to be as effective as a 16-hour infusion of oxytocin in prevention of intraoperative and postoperative blood loss after caesarean section ${ }^{[19]}$. Another study found that a single dose of carbetocin had the same efficacy compared to two-hour oxytocin infusion in prevention of intraoperative blood loss after removal of placental $^{[18]}$.

Elgafor El-Sharkwy et al. ${ }^{[19]}$ studied 380 patients and compared combination of sublingual misoprostol and oxytocin infusion with intravenous carbetocin in the 
prevention of PPH during cesarean delivery in high-risk patients. The authors concluded that combined misoprostoloxytocin was as effective as intravenous carbetocin in reducing the need for additional uterotonics ${ }^{[19]}$.

Some studies have demonstrated that misoprostol 400$600-\mu \mathrm{g}$ is as effective as oxytocin ${ }^{[4]}$ and a combination of misoprostol $200 \mu \mathrm{g}$ with oxytocin has been demonstrated to reduce blood loss and the need for additional uterotonics ${ }^{[20]}$.

A Chinese study ${ }^{[21]}$ reported that a $600-\mu \mathrm{g}$ dose of misoprostol was superior to oxytocin in the prevention of postpartum bleeding. Another systematic review ${ }^{[22]}$ which examined the use of prophylactic misoprostol during cesarean deliveries, included data from 17 studies (3174 patients). Generally, when compared to oxytocin, misoprostol alone did not demonstrate any significant improvements in the prevention of intra-and post-operative hemorrhage ${ }^{[22]}$. However, combination of misoprostoloxytocin was more effective than oxytocin alone in reducing intra- and post-operative hemorrhage during cesarean deliveries $^{[22]}$.

Other trials and reviews have examined the effectiveness of misoprostol during vaginal deliveries. Varying results have been reported. However, misoprostol has not been found to be superior to oxytocin in reducing postpartum blood loss and the use of additional uterotonics in general. Carbetocin is a recent innovation in the prevention of $\mathrm{PPH}^{[5]}$.

Carbetocin is currently approved for the prevention of uterine atony after cesarean delivery under spinal or epidural anesthesia in 23 countries $^{[5]}$. Carbetocin is characterized by a longer duration of action than oxytocin and has been demonstrated in many studies ${ }^{[23]}$ to have few adverse effects. Few studies are available that have compared carbetocin and oxytocin.

A systematic review of 11 studies $^{[5]}$ was done, in which four studies compared carbetocin $(100 \mu \mathrm{g}$ administered intravenously) with oxytocin in patients undergoing a cesarean delivery. In comparison with oxytocin, carbetocin demonstrated a statistically significant reduction in the use of additional uterotonics. However, no statistically significant difference was reported between carbetocin and oxytocin in terms of the risk of patients experiencing PPH (500-1000-mL blood loss) or severe PPH (N1000-mL blood loss $)^{[5]}$.

One study has found that carbetocin is as effective as a combination of misoprostol plus oxytocin in the reduction of $\mathrm{PPH}$ and the use of additional uterotonics ${ }^{[19]}$.

\section{CONCLUSION}

Carbetocin is superior to syntocinon and misoprostol in reducing blood loss and minimizing incidence of uterine atony in patients performing elective caesarean delivery with high risk factors.

Carbetocin is solely efficient in controlling postpartum hemorrhage and is associated with less need for further uterotonic agents or surgical haemostatic measures in comparison to syntocinon and misoprostol groups. It produces prolonged uterine tetanic spasm during and post cesarean delivery in comparison to syntocinon and misoprostol.

\section{CONFLICTS OF INTEREST}

There are no conflicts of interest.

\section{REFERENCES:}

1. Villar J, Valladares E, Wojdyla D, Zavaleta N, Carroli G, Velazco A, Caesarean delivery rates and pregnancy outcomes: the 2005 WHO global survey on maternal and perinatal health in Latin America. Lancet 2006;367(9525):1819-29.

2. Borruto F, Treisser A, Comparetto C. Utilization of carbetocin for prevention of postpartum hemorrhage after cesarean section: a randomized clinical trial. Arch Gynecol Obstet 2009;280(5):707-12.

3. World Health Organization. WHO recommendations for the prevention and treatment of postpartum haemorrhage. Geneva: World Health Organization; 2012.

4. Vimala N, Mittal S, Kumar S. Sublingual misoprostol versus oxytocin infusion to reduce blood loss at cesarean section. Int J Gynecol Obstet 2006;92(2):106-10.

5. Su LL, Chong YS, Samuel M. Carbetocin for preventing postpartum haemorrhage. Cochrane Database Syst Rev 2012;2, CD005457.

6. Chong Y-S, Su L-L, Arulkumaran S (2004) Current strategies for the prevention of postpartum haemorrhage in the third stage of labour. Curr Opin Obstet Gynecol 16:143-150

7. Peters NCJ, Duvekot JJ. Carbetocin for the prevention of postpartum hemorrhage: a systematic review. Obstet Gynecol Surv. 2009;64:129-35.

8. Chen CY, Su YN, Lin TH, Chang Y, Horng HC, Wang $\mathrm{PH}$, Carbetocin in prevention of postpartum hemorrhage: experience in a tertiary medical center of Taiwan. Taiwanese J Obstet Gynecol. 2016;55(6):804-9. 
9. Atke A, Vilhardt H. Uterotonic activity and myometrial receptor affinity of 1-deamino-1-carba2-tyrosine (Omethyl)-Oxytocin. Acta Endocrinol (Copenh). 1987;115:155-60

10. Leung SW, Ng PS, Wong WY, Cheung TH. A randomized trial of Carbetocin versus syntometrine in the management of the third stage of labour. BJOG. 2006;113:1459-64.

11. Rath W. Prevention of postpartum hemorrhage with the Oxytocin analogue Carbetocin. Eur J Obstet Gynecol Reprod Biol. 2009;147:15-20.

12. Moran C, Bhuinneain NM, Geary M, Cunningham S, Mckenna P, Gardiner J. Myocardial ischaemia in normal patients undergoing elective Caesarean section: a peripartum assessment. Anaesthesia. $2001 ; 56: 1051-8$

13. Gülmezoglu AM, Forna F, Villar J, Hofmeyr GJ. Prostaglandins for preventing postpartum haemorrhage. Cochrane Database Syst Rev 2007

14. Tang OS, Gemzell-Danielsson K, Ho PC (2007) Misoprostol: pharmacokinetic profiles, effects on the uterus and side-effects. Int J Gynaecol Obstet 99(Suppl 2):160-167

15. Attilakos G, Psaroudakis D, Ash J, Buchanan R, Winter C, Donald F, Hunt L, Draycott T. Carbetocin versus oxytocin for the prevention of postpartum haemorrhage following caesarean section: the results of a double-blind randomised trial. BJOG 2010;117:929-936.

16. Dansereau J, Joshi AK, Helewa ME, Doran TA, Lange IR, Luther ER, Double-blind comparison of carbetocin versus oxytocin in prevention of uterine atony after cesarean section. Am J Obstet Gynecol 1999;180:670-6.
17. Boucher M, Horbay GL, Griffin P, Deschamps Y, Desjardins C, Schulz M, Double-blind, randomized comparison of the effect of carbetocin and oxytocin on intraoperative blood loss and uterine tone of patients undergoing cesarean section. J Perinatol 1998;18:202-7.

18. Ali. A.A. Nasr A. Ahmed H. Rasheedy M. Badawy M. Carbetocin versus Oxytocin and Misoprostol in prevention of atonic post-partum hemorrhage in high risk patients planed for cesarean delivery. Int J Reprod Contracept Obstet Gynecol. 2018 Jan;7(1):10-14

19. Elgafor el Sharkwy IA. Carbetocin versus sublingual misoprostol plus oxytocin infusion for prevention of postpartum hemorrhage at cesarean section in patients with risk factors: a randomized, open trail study. Arch Gynecol Obstet 2013;288(6): 1231-6.

20. Fekih M, Jnifene A, Fathallah K, Ben Regaya L, Memmi A, Bouguizene S, Benefit of misoprostol for prevention of postpartum hemorrhage in cesarean section: a randomized controlled trial [in French]. J Gynecol Obstet Biol Reprod (Paris) 2009; 38(7):588-93

21. Zhao Y, Li X, Peng Y. Clinical study on reduction of postpartum bleeding in cesarean section bymisoprostol [in Chinese]. Zhonghua $\mathrm{Fu}$ Chan $\mathrm{Ke}$ Za Zhi 1998;33(7):403-5.

22. Conde-Agudelo A, Nieto A, Rosas-Bermudez A, Romero R. Misoprostol to reduce intraoperative and postoperative hemorrhage during cesarean delivery: a systematic review and metaanalysis. Am J Obstet Gynecol 2013;209(1):40.e1-40.e17.

23. Prata N, Bell S, Weidert K. Prevention of postpartum hemorrhage in low-resource settings: current perspectives. Int J Womens Health 2013;5:737-52. 